\title{
GRIK2 has a role in the maintenance of urothelial carcinoma stem-like cells, and its expression is associated with poorer prognosis
}

\author{
Ryuta Inoue ${ }^{1,2}$, Yoshihiko Hirohashi ${ }^{1}$, Hiroshi Kitamura ${ }^{3}$, Sachiyo Nishida ${ }^{1,2}$, Aiko \\ Murai $^{1}$, Akari Takaya ${ }^{1}$, Eri Yamamoto ${ }^{1}$, Masahiro Matsuki,2, Toshiaki Tanaka ${ }^{2}$, \\ Terufumi Kubo ${ }^{1}$, Munehide Nakatsugawa ${ }^{1}$, Takayuki Kanaseki ${ }^{1}$, Tomohide \\ Tsukahara $^{1}$, Noriyuki Sato ${ }^{1}$, Naoya Masumori ${ }^{2}$, Toshihiko Torigoe ${ }^{1}$ \\ ${ }^{1}$ Department of Pathology, Sapporo Medical University School of Medicine, Chuo-Ku, Sapporo 060-8556, Japan \\ ${ }^{2}$ Department of Urology, Sapporo Medical University School of Medicine, Chuo-Ku, Sapporo 060-8556, Japan \\ ${ }^{3}$ Department of Urology, Graduate School of Medicine and Pharmaceutical Science for Research, University of Toyama, \\ Toyama-Shi 930-0194, Japan
}

Correspondence to: Yoshihiko Hirohashi, email: hirohash@sapmed.ac.jp Toshihiko Torigoe, email: torigoe@sapmed.ac.jp

Keywords: cancer stem-like cells, ALDH1, GRIK2, urothelial carcinoma

Received: June 29, 2016

Accepted: February 20, 2017

Published: March 16, 2017

Copyright: Inoue et al. This is an open-access article distributed under the terms of the Creative Commons Attribution License (CC-BY), which permits unrestricted use, distribution, and reproduction in any medium, provided the original author and source are credited.

\section{ABSTRACT}

Cancer stem-like cells (CSCs)/cancer-initiating cells (CICs) are small subpopulation of cancer cells that are endowed with higher tumor-initiating ability, self-renewal ability and differentiation ability. CSCs/CICs could be isolated as high aldehyde dehydrogenase 1 activity cells (ALDH1 ${ }^{\text {high }}$ ) from various cancer samples. In this study, we isolated urothelial carcinoma CSCs/CICs as ALDH ${ }^{\text {high }}$ cells and investigated the molecular aspects. ALDH1 ${ }^{\text {high }}$ cells showed greater sphere-forming ability and higher tumor-initiating ability in immune-deficient mice than those of ALDH1 ${ }^{\text {low }}$ cells, indicating that CSCs/CICs were enriched in ALDH1 ${ }^{\text {high }}$ cells. CDNA microarray analysis revealed that an ionotropic glutamate receptor glutamate receptor, ionotropic, kainate 2 (GRIK2) was expressed in ALDH1 ${ }^{\text {high }}$ cells at a higher level than that in ALDH1 ${ }^{\text {low }}$ cells. GRIK2 gene knockdown by siRNAs decreased the sphere-forming ability and invasion ability, whereas GRIK2 overexpression increased the sphere-forming ability, invasion ability and tumorigenicity, indicating that GRIK2 has a role in the maintenance of CSCs/CICs. Immunohistochemical staining revealed that higher levels of GRIK2 and ALDH1 expression were related to poorer prognosis in urinary tract carcinoma cases. The findings indicate that GRIK2 has a role in the maintenance of urothelial CSCs/CICs and that GRIK2 and ALDH1 can be prognosis prediction markers for urinary tract carcinomas.

\section{INTRODUCTION}

Urothelial carcinomas including bladder cancer, urethral cancer, renal pelvic cancer and ureteral cancer are common urological cancers. Metastatic urothelial carcinoma (UC) is relatively sensitive to chemotherapy with a response rate of $50-70 \%$; however, the three-year survival rate is less than $20 \%$ due to the high recurrence rate [1]. Thus, overcoming the problems of recurrence and treatment resistance is essential to cure urothelial cancer. Recent studies have revealed that cancer stemlike cells (CSCs)/cancer-initiating cells (CICs) are the major mechanisms of cancer recurrence and distant metastasis after treatments $[2,3]$. Tumors are comprised of heterogeneous cell populations, and a small distinct sub-population has higher tumor-initiating ability, selfrenewal ability and differentiation ability according to the cancer stem cell theory [3]. CSCs/CICs could be identified from urothelial carcinoma samples using several methods including the use of cell surface marker $\mathrm{CD}_{4} 4^{+}$or $67-\mathrm{kDa}$ 
laminin receptor, side population analysis using Hoechst 33342 or Dye-cycle violet, and ALDH1 activity based on the ALDEFLUOR assay [4-8].

ALDH1 enzymes have roles in epithelial development and homeostasis. Deregulation of this class of enzymes is implicated in multiple cancers. ALDH1 is a cytoplasmic isoform of ALDH, and high levels of its activity are seen not only in hematopoietic stem cells but also in solid cancers [9-15]. Furthermore, ALDH1 enzymes are related to drug resistance, cell proliferation, cell differentiation and response to oxidative stress. Glutamate receptor, ionotropic, kainate 2 (GRIK2) belongs to an ionotropic glutamate receptor and is broadly expressed in central nerve system and plays a major role in nerve excitation [16]. GRIK2 is expressed in some normal organs including stomach, and a recent study revealed that GRIK2 transcription was repressed by hypermethylation of promoter region in gastric cancers, suggesting that GRIK2 might be a novel tumor suppressor gene in gastric cancers $[17,18]$. Recently, polymorohism of GRIK2 TT (rs1335022) was associated with high risk of oral cancer in tobacco habitués, indicating that GRIK2 might be related to carcinogenesis [19]. However, there is no report describing the relation of $\mathrm{CSC} / \mathrm{CIC}$ and GRIK2.

Urothelial carcinoma contains a small population of CSCs/CICs, and we previously reported that ALDH1positive upper urinary tract carcinoma had a poor prognosis compared with that of ALDH1-negative tumors. [15] In this study, we isolated urothelial carcinoma CSCs/ $\mathrm{CICs}$, screened the CSC/CIC-specific genes and identified GRIK2 is preferentially expressed in urothelial CSCs/ CICs. We furthermore analyzed the functions of GRIK2 by gene knockdown using siRNAs and gene overexpression, and analyzed the clinical significance of GRIK2 protein expression in urothelial carcinomas.

\section{RESULTS}

\section{Isolation of UC stem-like cells based on aldehyde dehydrogenase 1A1 activity assay}

Aldehyde dehydrogenase 1 (ALDH1) activity is a cancer stem-like cells(CSCs)/cancer-initiating cells(CICs) marker of various cancers [9-13]. We thus investigated whether ALDH1 activity is applicable to isolate urothelial $\mathrm{CSCs} / \mathrm{CICs}$. ALDH $1^{\text {high }}$ cells were detectable in all urothelial carcinoma cell lines except for HT1376 and SW780 cell lines. The ratios of ALDH $1^{\text {high }}$ cells in UM-UC3, T24, TCCSUP, 5637, J82 and RT4 cell lines were $10.2 \%, 16.2 \%, 15.5 \%, 28.7 \%, 1.4 \%$ and $4.0 \%$, respectively (Figure 1A). However, RT-PCR and Western blot analysis revealed that $A L D H 1 A 1 \mathrm{mRNA}$ and ALDH1 protein were not expressed in T24 and 5637 cells (Figure $1 \mathrm{~B}$ and $1 \mathrm{C})$. We therefore further analyzed ALDH $1^{\text {high }}$ cells derived from UM-UC3, TCCSUP, J82 and RT4 cells.
A sphere-forming assay was performed to analyze ALDH $1^{\text {high }}$ cells derived from UM-UC3, TCCSUP, J82, and RT4 cells. Sphere-forming ability was evaluated using $2 \times 10^{2}$ of sorted ALDH $1^{\text {high }}$ and ALDH1 $1^{\text {low }}$ cells in Ultra-Low Attachment Surface culture dishes. Only ALDH $1^{\text {high }}$ cells derived from UM-UC3 cells showed higher sphere-forming ability than that of ALDH $1^{\text {low }}$ cells (Figure 1D). To exclude mechanical damage by cell sorting, we examined sphere-forming ability in medium containing 10\% FBS. Little sphere formation was observed in ALDH $1{ }^{\text {high }}$ cells derived from TCCSUP and J82 cells (Supplementary Figure 1). Mechanical damage caused by the cell sorter may induce cell death of TCCSUP and $\mathrm{J} 82$ cells.

To examine the tumorigenic potential of ALDH $1^{\text {high }}$ cells derived from UM-UC3 cells in vivo, we performed xenograft transplantation of ALDH $1^{\text {high }}$ and ALDH $1^{\text {low }}$ cells into NOD/SCID mice. ALDH1 $1^{\text {high }}$ cells initiated the formation of tumors in all of the 6 mice, whereas ALDH $1^{\text {low }}$ cells initiated the formation of tumors in only 3 of the 6 mice. Tumors derived from ALDH $1^{\text {high }}$ cells were significantly larger than those derived from ALDH1 1ow cells $(P<0.05)$ (Figure 1E). These results indicated that ALDH $1^{\text {high }}$ cells derived from UM-UC3 cells were enriched with $\mathrm{CSCs} / \mathrm{CICs}$, and we therefore used UMUC3 cells in the following analysis.

\section{ALDH1 ${ }^{\text {high }}$ cells have higher invasion ability and are resistant to cisplatin}

UC has properties of local invasion and lymph node metastasis. We therefore performed an invasion assay to address the invasion ability of UC CSCs/CICs. ALDH $1^{\text {high }}$ cells derived from UM-UC3 cells showed significantly greater invasion ability than that of ALDH1 1ow cells $(P<0.05)$ (Figure 2A). Chemotherapy is a key treatment for metastatic advanced UCs and cisplatin is the key drug for UCs. We thus analyzed the sensitivity to chemotherapy of ALDH $1^{\text {high }}$ cells and found that ALDH $1^{\text {high }}$ cells were more resistant to cisplatin than were ALDH1 ${ }^{\text {low }}$ cells (Figure 2B).

\section{Identification of ALDH1 ${ }^{\text {high }}$ cell-related genes}

To address the gene expression profiles of ALDH1 $1^{\text {high }}$ cells, we performed cDNA microarray screening using ALDH $1^{\text {high }}$ and $\mathrm{ALDH} 1^{\text {low }}$ cells derived from UM-UC3 cells. Approximately 50 genes were upregulated in ALDH1 ${ }^{\text {high }}$ cells compared with the genes in ALDH1 1ow cells (Supplementary Table 1). We screened the expression profiles in normal adult tissues by RTPCR using specific primers for candidate genes and found that the expression level of glutamate receptor, ionotropic, kainate 2 (GRIK2) was expressed at relatively low levels in normal tissues (Supplementary Figure 2). 
Immunohistochemical staining revealed that GRIK2 was expressed in UC cells (Supplementary Figures 3A and 3B). The expression of GRIK2 in ALDH1 ${ }^{\text {high }}$ cells was confirmed by RT-PCR (Figure 2C), quantitative real-time PCR (qRT-PCR) (Figure 2D) and immunohistochemichal staining using tumors derived from ALDH1 $1^{\text {high }}$ cells and ALDH1 ${ }^{\text {low }}$ cells (Figure 2E).

\section{Functional analysis of GRIK2 by siRNA- mediated knockdown}

GRIK2 belongs to the kainate family of glutamate receptors and it is a predominant neurotransmitter receptor in the mammalian brain and is activated in various normal neurophysiologic processes. Although GRIK2

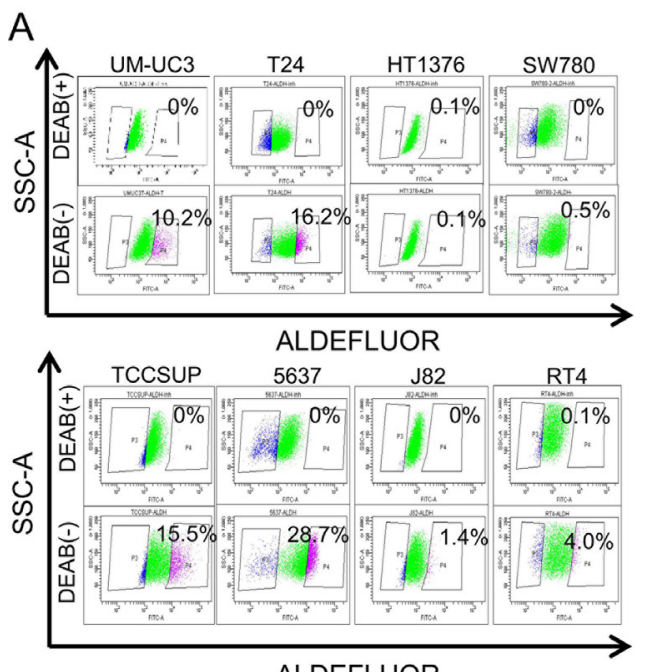

ALDEFLUOR

\section{B}

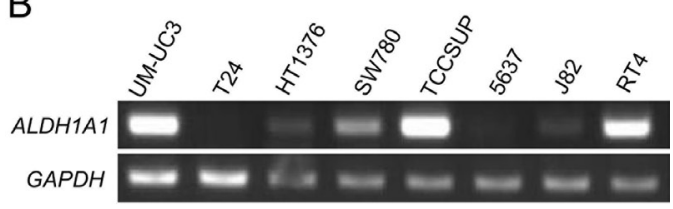

C

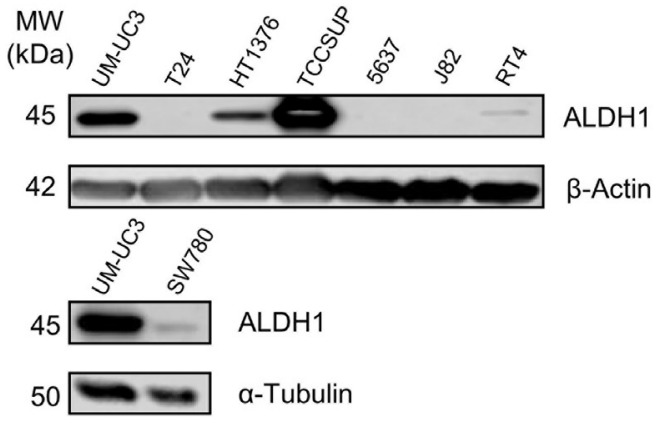

$\mathrm{D}$

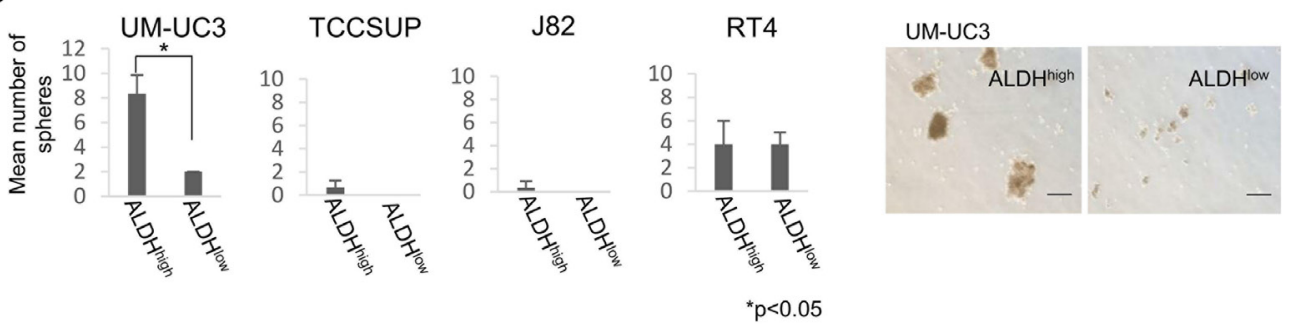

$E$

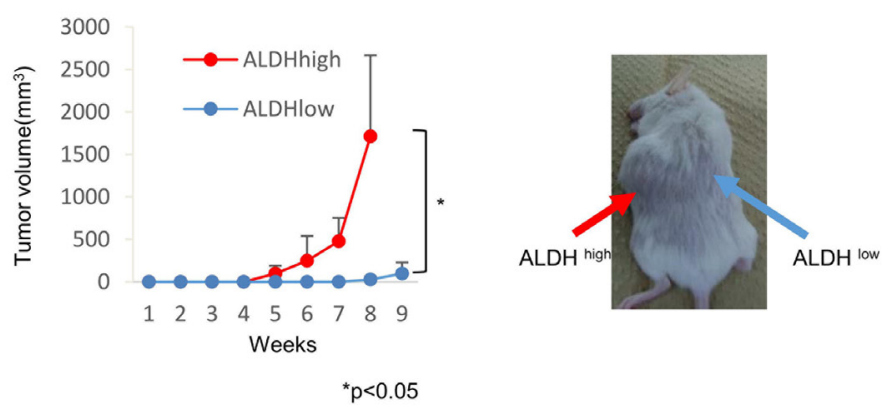

Figure 1: Expression of ALDH1A1 and isolation of UC CSCs/CICs. (A) ALDEFLUOR assay of urothelial carcinoma cell lines. $S S C$ - $A$, single strand analysis. FITC-A, fluorescein isothiocyanate analysis. Percent indicates ALDH1-positive rate. (B) RT-PCR analysis of urothelial carcinoma cell lines. Expression of ALDH1A1 mRNA was examined by RT-PCR. GAPDH was used as a positive control. (C) Western blot analysis of ALDH1 protein. Urothelial carcinoma cell lines were analyzed with anti-ALDH1 mAb (clone: 44/ALDH). $\beta$-Actin and $\alpha$-Tubulin were used as positive controls. (D) Sphere-forming assay. ALDH1 ${ }^{\text {high }}$ and ALDH1 ${ }^{\text {low }}$ cells derived from UM-UC3, TCCSUP, J82 and RT4 cells were incubated in serum-free Dulbecco's modified Eagles medium (DMEM)/F12 media with growth factors. Each value is the mean number of spheres $\pm \mathrm{SD}$. ${ }^{*} P$ values. Black bar is $100 \mu \mathrm{m}$. (E) Tumor growth curves of ALDH1 ${ }^{\text {high }}$ and ALDH1 ${ }^{\text {low }}$ cells derived from UM-UC3 cells injected in NOD/SCID mice, and representative views of mouse tumors. Each value is the mean tumor volume $\pm \mathrm{SD} .{ }^{*} P$ values. 
is distributed throughout the central nervous system, its physiological significance in cancer stem-like cells has not been determined yet [20]. We thus analyzed the function of GRIK2 in UC cells by GRIK2 knockdown using siRNAs and GRIK2 overexpression. Gene-specific knockdown of GRIK2 mRNA was confirmed by qRT-PCR (Figure 3A). To analyze the role of GRIK2 in UC CSCs/CICs, ALDEFLUOR assay, invasion assay and sphere-forming assay were performed. GRIK2 knockdown by siRNAs decreased the ratios of ALDH $1^{\text {high }}$ cells (Figure $3 \mathrm{~B}$ ). GRIK2 knockdown by siRNAs significantly decreased invasion ability and sphere-forming ability (Figure 3C and 3D). A limiting dilution assay revealed that estimated $\mathrm{CSCs} / \mathrm{CICs}$ frequency was significantly decreased by GRIK2 knockdown by siRNAs (Table 1).

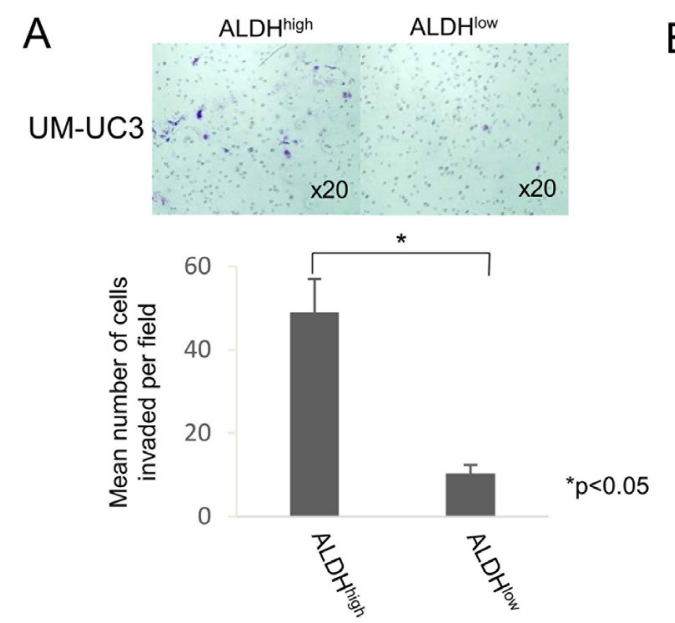

B
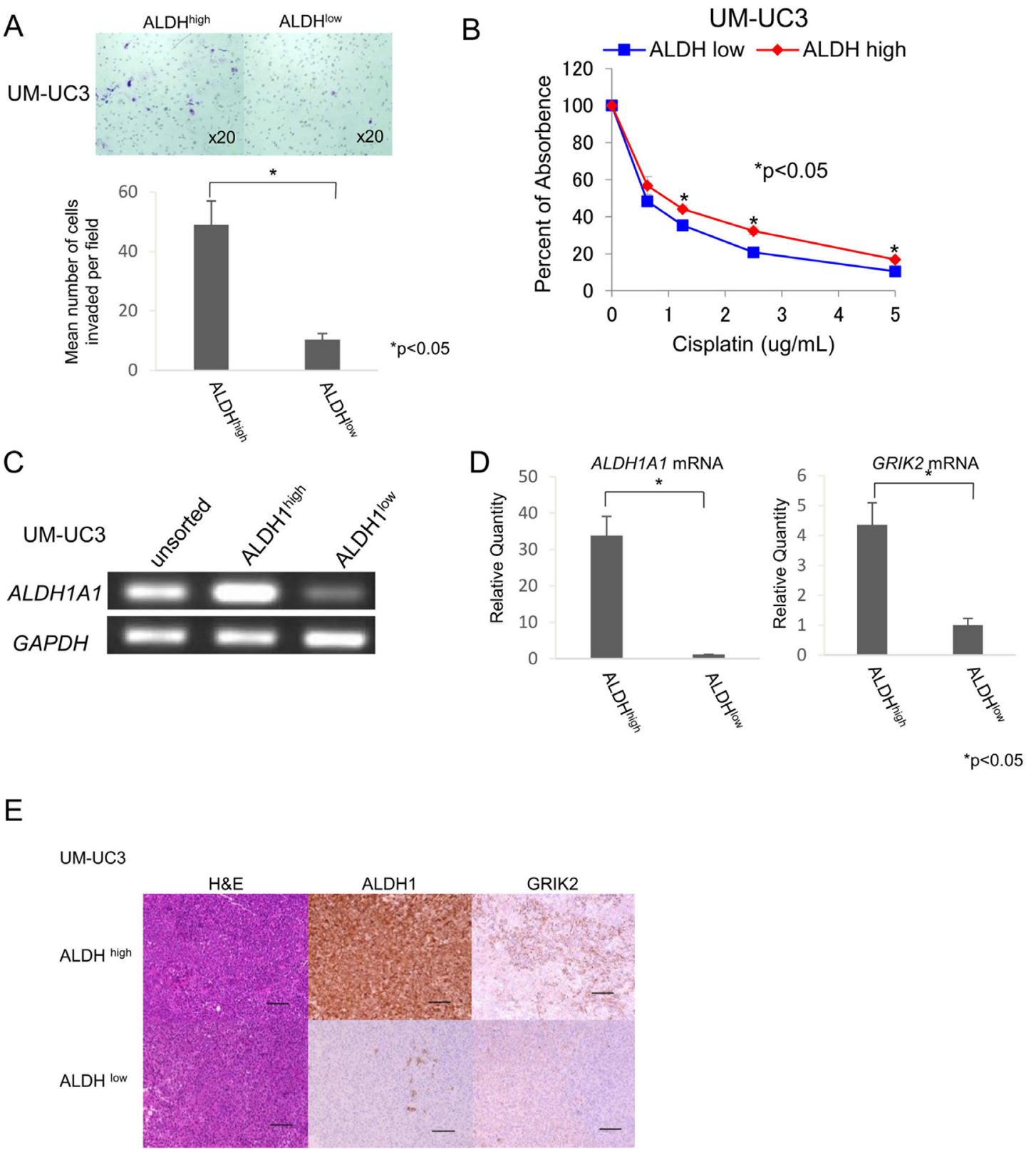

Figure 2: ALDH1 ${ }^{\text {high }}$ cells have properties of CSCs/CICs. (A) Matrigel invasion assay. Matrigel-invading cells derived from $\mathrm{ALDH}^{\text {high }}$ and $\mathrm{ALDH}^{\text {low }}$ cells of UM-UC3 cells. Magnification of images: $\mathrm{x} 20$. Each value is the mean number of invading cells \pm SD. *P values. (B) Cell viability in cisplatin. Cell viability was analyzed by the WST-1 assay. Percent absorbance of ALDH ${ }^{\text {high }}$ and ALDH ${ }^{\text {low }}$ cells of UM-UC3 cells treated with cisplatin. Each value is the mean percent of absorbance $\pm \mathrm{SD} .{ }^{*} P$ values. (C) RT-PCR analysis with unsorted, $\mathrm{ALDH}^{\text {high }}$ and $\mathrm{ALDH}^{\text {low }}$ cells of UM-UC3 cells. Expression of $A L D H 1 A 1 \mathrm{mRNA}$ was examined by RT-PCR. GAPDH was used as a positive control. (D) Quantitative real-time PCR. Relative quantities of ALDH1A1 and GRIK2 mRNAs of ALDH ${ }^{\text {high }}$ and ALDH $^{\text {low }}$ cells of UM-UC3 cells. Each value is the mean relative quantity $\pm \mathrm{SD}$. $* P$ values. (E) Histological images of ALDH ${ }^{\text {high }}$ and ALDH $^{\text {low }}$ tumors derived from UM-UC3 cells. Hematoxylin-eosin staining (H\&E), ALDH1 immunohistochemical staining and GRIK2 immunohistochemical staining of $\mathrm{ALDH}^{\text {high }}$ and $\mathrm{ALDH}^{\text {low }}$ tumors. Black bar is $100 \mu \mathrm{m}$. 


\section{Functional analysis of GRIK2 by overexpression}

GRIK2 was preferentially expressed in ALDH1 $1^{\text {high }}$ cells derived from UM-UC3 cells. Expression of GRIK2 was also detectable in J82 cells, but it was not detected in T24 cells (Figure 4A). To elucidate the functions of GRIK2 we established GRIK2 overexpressed cells of UM-UM3 cells and T24 cells. GRIK2 gene expression and GRIK2 protein expression were confirmed by RTPCR and immunohistochemical staining (Figure 4B and 4F). Matrigel invasion assay, sphere-forming assay and xenograft transplantation in NOD/SCID mice using GRIK2 stable transformants were performed. The matrigel invasion assay revealed that overexpression of GRIK2 increased the invasion ability of T24 cells $(P<0.05)$ (Figure 4C). GRIK2-overexpressed cells showed greater sphere-forming ability than that of control plasmid transfected (T24/Mock) cells $(P<0.05)$ (Figure 4D). A limiting dilution assay revealed that overexpression of GRIK2 significantly increased the frequencies of CSCs/CICs of UM-UC3 cells and T24 cells (Table 1). To evaluate tumorigenicity ability in vivo, xenograft transplantation of T24/GRIK2 and T24/Mock cells in NOD/SCID mice was performed. T24/GRIK2 cells initiated the formation of tumors in all 3 mice by day 63, whereas T24/Mock cells initiated the formation
A

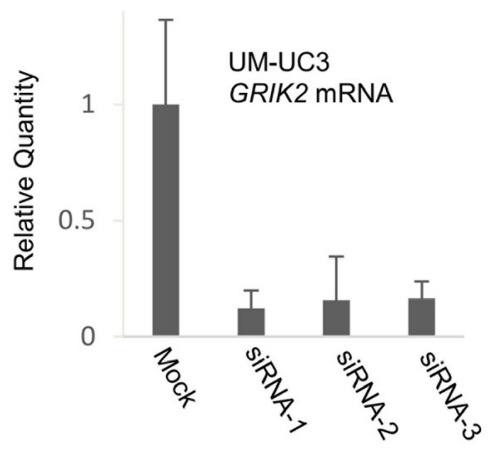

C

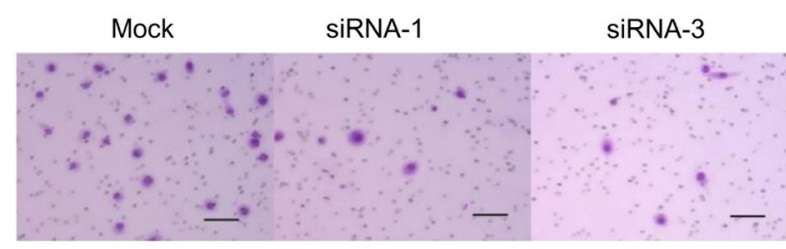

D

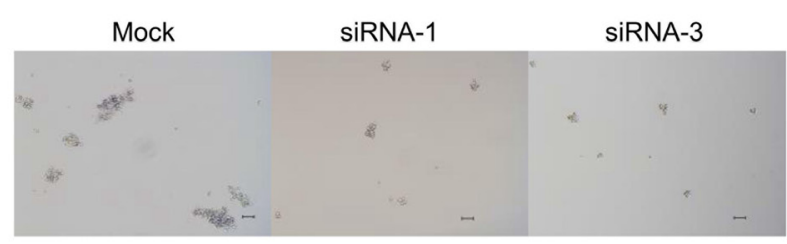

B

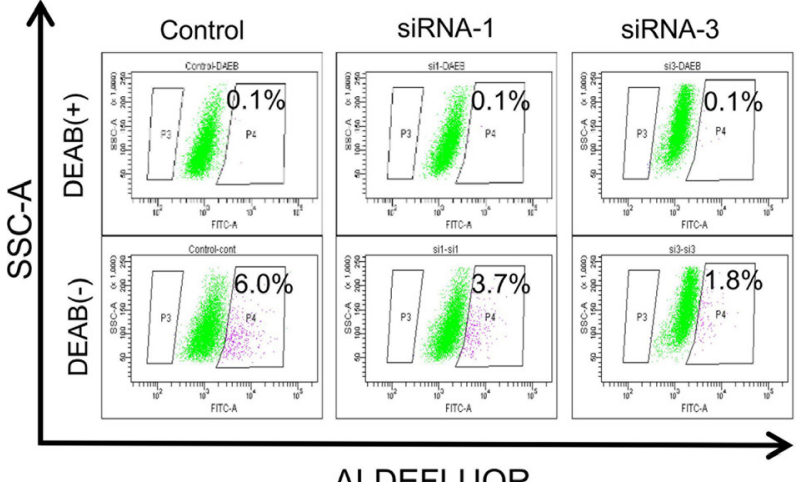

ALDEFLUOR
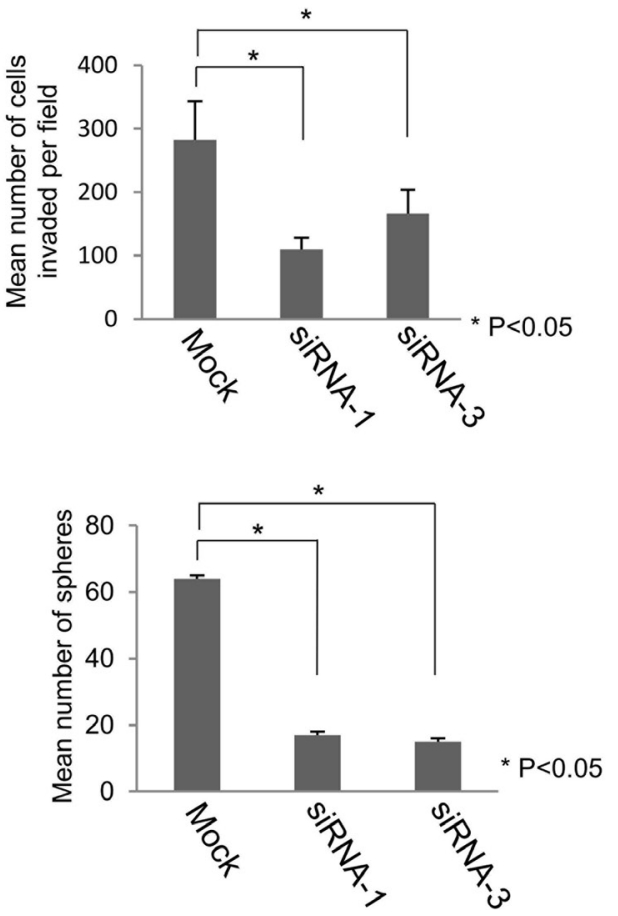

Figure 3: Functional analysis of GRIK2 by siRNA-mediated mRNA knockdown. (A) Quantitative real-time PCR. Relative quantity of GRIK2 mRNA of UM-UC3 si-mediated mRNA knockdown cells. (B) ALDEFLUOR assay of UM-UC3 GRIK2 knockdown cells. SSC-A, single strand analysis. FITC-A, fluorescein isothiocyanate analysis. Percent indicates ALDH1 positivity. (C) Matrigel invasion assay. Matrigel-invading cells derived from UM-UC3 GRIK2 knockdown cells. Black bar is $100 \mu \mathrm{m}$. Each value is the mean number of invading cells \pm SD. ${ }^{*} P$ values. (D) Sphere-forming assay. Spheres derived from UM-UC3 GRIK2 knockdown cells. Black bar is $100 \mu$ m. Each value is the mean number of spheres $\pm \mathrm{SD} . * P$ values. 
Table 1: Stem cell frequencies of GRIK2 or ALDH1A1 overexpressed and GRIK2 knocdown cells

\begin{tabular}{|c|c|c|c|c|c|c|c|}
\hline \multirow[t]{2}{*}{ Cells } & \multicolumn{4}{|c|}{ sphere-formation/well } & \multirow{2}{*}{$\begin{array}{c}\text { CSC } \\
\text { frequency }\end{array}$} & \multirow[t]{2}{*}{$95 \% \mathrm{CI}$} & \multirow[t]{2}{*}{$\dagger P$ value } \\
\hline & 1 cell $/$ well & 10 cells/well & 100 cells/well & 1000 cells/well & & & \\
\hline UM-UC3/control siRNA & $0 / 24$ & $7 / 24$ & $14 / 24$ & $24 / 24$ & 1 in 86 & $54.2-137$ & \\
\hline UM-UC3/siRNA1 & $0 / 24$ & $1 / 24$ & $7 / 24$ & $17 / 24$ & 1 in 625 & $401.5-975$ & ${ }^{* *} 9.18 \mathrm{e}-10$ \\
\hline UM-UC3/siRNA2 & $0 / 24$ & $1 / 24$ & $4 / 24$ & $19 / 24$ & 1 in 602 & $386.9-937$ & ${ }^{* *} 3.32 \mathrm{e}-09$ \\
\hline UM-UC3/siRNA3 & $0 / 24$ & $0 / 24$ & $1 / 24$ & $17 / 24$ & 1 in 923 & $575.3-1481$ & ${ }^{* *} 2.25 \mathrm{e}-12$ \\
\hline UM-UC3/Mock & $0 / 32$ & $3 / 32$ & $16 / 32$ & $22 / 32$ & 1 in 494 & $337.6-722$ & \\
\hline UM-UC3/GRIK2 & $0 / 32$ & $6 / 32$ & $22 / 32$ & $30 / 32$ & 1 in 153 & $97.6-239$ & ${ }^{* *} 3.44 \mathrm{e}-06$ \\
\hline T24/Mock & $0 / 32$ & $1 / 32$ & $8 / 32$ & $15 / 32$ & 1 in 1106 & $720-1698$ & \\
\hline T24/GRIK2 & $0 / 32$ & $1 / 32$ & $12 / 32$ & $21 / 32$ & 1 in 642 & $437-943$ & ${ }^{*} 0.0473$ \\
\hline T24/ALDH1A1 & $0 / 32$ & $2 / 32$ & $13 / 32$ & $17 / 32$ & 1 in 769 & $518-1141$ & 0.188 \\
\hline 5637/Mock & $1 / 32$ & $3 / 32$ & $16 / 32$ & $20 / 32$ & 1 in 546 & $373-799$ & \\
\hline 5637/ALDH1A1 & $1 / 32$ & $6 / 32$ & $20 / 32$ & $29 / 32$ & 1 in 195 & $125-305$ & ${ }^{* *} 2.73 \mathrm{e}-05$ \\
\hline
\end{tabular}

CSC frequency was caluculated by ELDA website. "Defference with Mock cells or control siRNA transfected cells were caliculated by Chi-square test. ${ }^{*} P<0.05,{ }^{* *} P<0.01$. CSC, cancer stem cell; CI, confidence interval.

of tumors in 2 of the 3 mice by day 63 . Tumors derived from T24/GRIK2 cells were significantly larger than those derived from T24/Mock cells $(P<0.05)$ (Figure 4E).

\section{GRIK2 and ALDH1 expression and clinicopathological features in patients with upper urinary tract urothelial carcinoma}

We previously described ALDH1 expression is associated with poor prognosis in patients with upper urinary tract UC [15], and ALDH1 is a well accepted marker for $\mathrm{CSCs} / \mathrm{CICs}$. However, direct relation between ALDH1 and $\mathrm{CSCs} / \mathrm{CICs}$ is still elusive. To elucidate ALDH1 in CSCs/CICs, we established ALDH1A1 overexpressed cells using ALDH1-negative cells (5637 cells and T24 cells) (Supplementary Figure 4). Limiting dilution assay revealed that overexpression of ALDH1A1 in 5637 cells significantly increased CSCs/CICs frequency, and T24 cells ALDH1A1 overexpressed cells showed tendency of increase CSCs/ CICs frequency but the difference did not reach statistical significance (Table 1). Thus, both GRIK2 and ALDH1 are related to CSCs/CICs; however, ALDH1A1 did not change the expression of GRIK2 in 5637 cells (Supplementary Figure 4). To evaluate the relationship between ALDH1 and GRIK2, we analyzed data for 113 patients who underwent radical nephroureterectomy (Table 2). GRIK2-positive cells and ALDH1-positive cells (Figure 5A) were observed in 87 $(77 \%)$ and $36(32 \%)$ of the patients, respectively. GRIK2negative cells and ALDH1-negative cells were observed in 26 $(23 \%)$ and $77(68 \%)$ of the patients (Figure 5B), respectively. GRIK2-positive cases showed a higher rate of lymph node metastasis $(13 \%, P=0.047)$, high grade of tumor $(86 \%$,
$P=0.0002)$ and lymphovascular invasion $(37 \%, P=0.009)$ compared with GRIK2-negative cases. ALDH1-positive cases showed a higher rate of pathological T stage (pT2 or more: $77 \%, P=0.020)$, high grade of tumor $(92 \%$, $P=0.0099)$ and lymphovascular invasion $(47 \%, P=0.012)$ (Table 3). These results indicated that GRIK2 and ALDH1 were associated with high invasion ability.

We evaluated the association of GRIK2 and/or ALDH1 with survival and recurrence. The 3-year cancerspecific survival rates of patients with GRIK2-positive and GRIK2-negative tumors were $90.2 \%$ and $70.1 \%$ $(P=0.046)$, respectively (Figure 6A). The 3-year cancerspecific survival rates of patients with ALDH1-positive and ALDH1-negative tumors were $85.4 \%$ and $50.9 \%$ $(P<0.01)$, respectively (Figure 6B). Thus, both the expression of GRIK2 and that of ALDH1 were correlated with poorer prognosis. To evaluate the impact of the combination of GRIK2 and ALDH1, we classified the patients into three groups according to the immunohistochemical staining of GRIK2 and ALDH1: category 1 (both GRIK2 and ALDH1 negative), category 2 (GRIK2 or ALDH1 positive), and category 3 (both GRIK2 and ALDH1 positive) (Supplementary Table 2). The 3-year cancer-specific survival rates of patients in categories 1,2 and 3 were $93.8 \%, 81.8 \%$ and $44.9 \%$, respectively $(P<0.01$, Figure 6C). However, intravesical recurrencefree survival rates of patients with GRIK2 and/or ALDH1 expressing tumors were not significantly different $(P=0.279$, Supplementary Figure 5).

These results indicated that the novel UC CSC/CICrelated gene GRIK2 and ALDH1A1 have a role in the maintenance of UC CSCs/CICs and that the expression of 
Table 2: Characteristics of the 113 patients

\section{Characteristics}

Median age in years (range)

$69(32-88)$

Median follow-up in months (range)

$27(2-142)$

Sex

Male

$80(71)$

Female

Side

Right

Left

$62(55)$

Bilateral

Primary site (main)

Renal pelvis

64 (57)

Ureter

Both

Pathological stage

Stage 0a

Stage 0is

Stage I

Stage II

Stage III

Stage IV

Chemotherapy

Neoadjuvant

Adjuvant

$5(4)$

Values are n (\%) except where mentioned otherwise.

GRIK2 combined with ALDH1 is a novel prognostic marker for UC cases.

\section{DISCUSSION}

In this study, we successfully isolated urothelial carcinoma CSCs/CICs using the UC cell line UM-UC3 based on the ALDH1 activity assay and identified the glutamate receptor, ionotropic, kainate 2 (GRIK2) gene as a gene involved in the invasion ability of ALDH1 high activity cells. To our knowledge, this is the first report showing that ALDH $1{ }^{\text {high }}$ cells can also be isolated from UMUC3 urothelial carcinoma cells by the ALDEFLUOR assay and that ALDH1 $1^{\text {high }}$ cells have stem cell characteristics.

The UC cell lines RT4, T24 and 5637 or TCCSUP, T24 and 5637 were used in previous studies on ALDH1 
Table 3: GRIK2/ALDH1 expression and pathological factors in patients with upper urinary tract urothelial carcinoma

\begin{tabular}{|c|c|c|c|c|c|c|}
\hline \multirow[b]{2}{*}{ Variable } & \multicolumn{3}{|c|}{ GRIK2 } & \multicolumn{3}{|c|}{ ALDH1 } \\
\hline & Positive (\%) & $\begin{array}{c}\text { Negative } \\
(\%)\end{array}$ & $p$-value & Positive (\%) & $\begin{array}{c}\text { Negative } \\
(\%)\end{array}$ & $p$-value \\
\hline Number of patients & $87(77)$ & $26(23)$ & & $36(32)$ & $77(68)$ & \\
\hline Pathological T stage & & & 0.126 & & & 0.020 \\
\hline $\mathrm{pTa}$ & $11(13)$ & $4(15)$ & & $4(11)$ & $11(14)$ & \\
\hline pTis & $1(1)$ & $1(4)$ & & $2(6)$ & $0(0)$ & \\
\hline pT1 & $8(9)$ & $8(31)$ & & $2(6)$ & $14(18)$ & \\
\hline pT2 & $20(23)$ & $4(15)$ & & $9(25)$ & $15(20)$ & \\
\hline pT3 & $43(49)$ & $8(31)$ & & $15(41)$ & $36(47)$ & \\
\hline pT4 & $4(5)$ & $1(4)$ & & $4(11)$ & $1(1)$ & \\
\hline Pathological N stage & & & 0.047 & & & 0.412 \\
\hline pN0 & $76(87)$ & $26(100)$ & & $31(86)$ & $71(92)$ & \\
\hline $\mathrm{pN} 1$ & $5(6)$ & $0(0)$ & & $3(8)$ & $2(3)$ & \\
\hline $\mathrm{pN} 2$ & $6(7)$ & $0(0)$ & & $2(6)$ & $4(5)$ & \\
\hline Grade & & & 0.0002 & & & 0.0099 \\
\hline Low & $12(14)$ & $13(50)$ & & $3(8)$ & $22(29)$ & \\
\hline High & $75(86)$ & $13(50)$ & & $33(92)$ & $55(71)$ & \\
\hline $\begin{array}{l}\text { Lymphovascular } \\
\text { invasion }\end{array}$ & & & 0.009 & & & 0.012 \\
\hline Negative & $55(63)$ & $23(88)$ & & $19(53)$ & $59(77)$ & \\
\hline Positive & $32(37)$ & $3(12)$ & & $17(47)$ & $18(23)$ & \\
\hline
\end{tabular}

activity of UC CSCs/CICs $[8,21]$. However, RT-PCR and Western blot showed that $A L D H 1 A 1$ and ALDH1 were not expressed in T24 and 5637 cells, in this study. RT4 cells were positive in the ALDEFLUOR assay, but ALDH1 $1^{\text {high }}$ cells derived from RT4 cells did not show grater sphereforming ability than that of ALDH $1^{\text {low }}$ cells. Thus, we did not use RT4 cells for xenograft transplantation in NOD/ SCID mice. However, in a previous study, ALDH1 $1^{\text {high }}$ cells derived from RT4 cells showed high colony-forming ability by a soft agar assay and high tumorigenicity ability by xenograft transplantation in NOD/SCID mice [8]. These different results might be due to differences in assay and cell culture conditions. TCCSUP cells showed a high level of ALDH1 expression, but ALDH1 $1^{\text {high }}$ cells derived from TCCSUP cells did not show high sphere-forming ability, and these results are compatible with results of a previous study. [21] ALDH1 was expressed in TCCSUP and J82 cells; however, only a few spheres were observed in the sphere-forming assay. This result might have been caused by mechanical damage caused by the cell sorter because only a few colonies were observed in the condition with $10 \%$ FBS. Thus, UM-UC3 is a reasonable source for study in $\mathrm{UC} \mathrm{CSCs} / \mathrm{CICs}$.

GRIK2 is one of the glutamate receptors that is the predominant neurotransmitter receptor in the mammalian brain and is activated in various normal neurophysiologic processes. Glutamate receptors are membrane proteins and are classified into two major groups: metabotropic glutamate receptors and ionotropic glutamate receptors. The ionotropic glutamate receptors include $N$-methylD-asparate (NMDA), $\alpha$-amino-3-hydroxy-5-methylisoxazole-4-propionate (AMPA) and kainate glutamate receptors. GRIK2 (or GluR6) is one of the five members of the kainate glutamate receptor subgroup, which also includes GluR5-7, KA1 and KA2. Although, kainate receptors are distributed throughout the central nervous system, their physiological significance in cancer cells is not known well [17, 20, 22].

There have been a few reports in which the association between GRIK2 and cancers was described. 
GRIK2 was reported to be a potential tumor suppressor gene in gastric cancer [17]. GRIK2 was expressed in normal gastric tissue; however, its expression was repressed in gastric cancer tissues by GRIK2 promoter region methylation. Furthermore, overexpression of GRIK2 in gastric cancer cells decreased colony formation and cell migration. These findings indicate that GRIK2 is a tumor suppressor gene. Recently, polymorohism of GRIK2 TT (rs1335022) was associated with oral cancer [19]. However, the SNP region is in an intron and the SNP does not alter mature GRIK2 protein sequence. Our findings indicate oncogenic potential of GRIK2 in
A

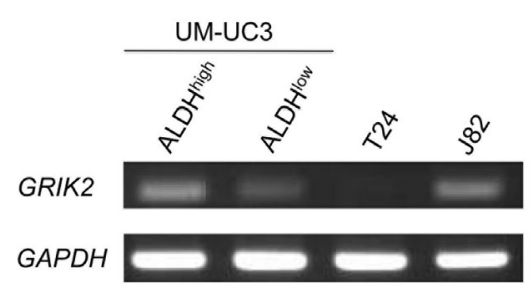

C

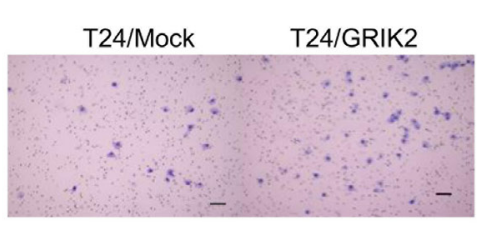

D

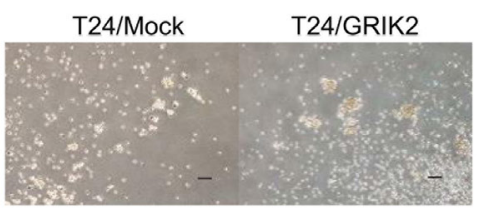

$E$

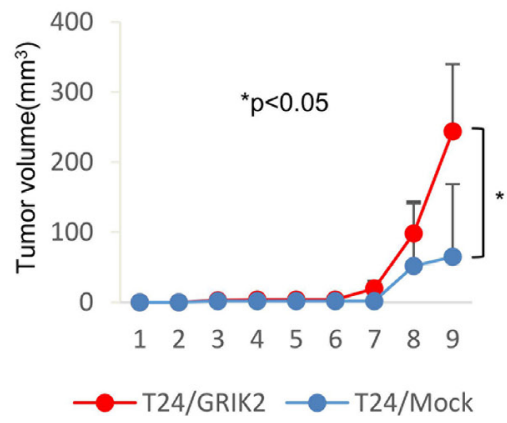

B

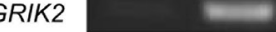

GAPDH $=$
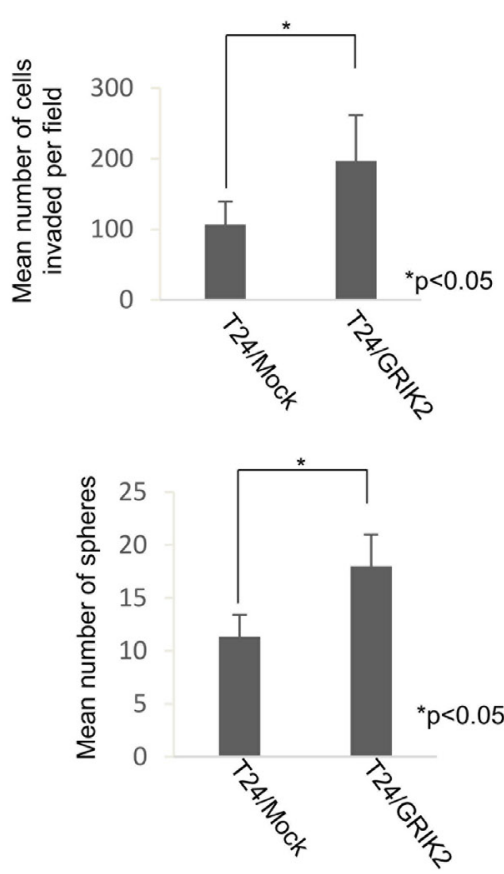

F

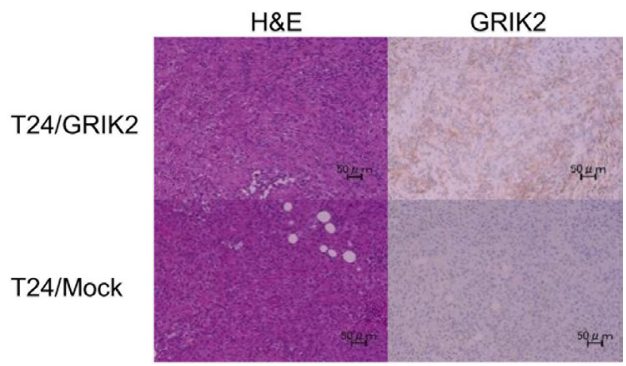

Figure 4: Functional analysis of GRIK2 by stable tranformants. (A) RT-PCR analysis with ALDH ${ }^{\text {high }}$ and ALDH ${ }^{\text {low }}$ of UMUC3, T24 and J82 cells. Expression of GRIK2 mRNA was examined by RT-PCR. GAPDH was used as a positive control. (B) RT-PCR analysis with T24/Mock and T24/GRIK2. Expression of GRIK2 mRNA was examined by RT-PCR. GAPDH was used as a positive control. (C) Matrigel invasion assay. Matrigel-invading cells derived from T24/Mock and T24/GRIK2 cells. Black bar is $100 \mu \mathrm{m}$. Each value is the mean number of invading cells $\pm \mathrm{SD}$. ${ }^{*} P$ values. (D) Sphere-forming assay. Spheres derived from T24/Mock and T24/GRIK2 cells. Black bar is $100 \mu \mathrm{m}$. Each value is the mean number of spheres \pm SD. $* P$ values. (E) Tumor growth curves of T24/Mock and T24/GRIK2 cells injected in NOD/SCID mice. Each value is the mean tumor volume $\pm \mathrm{SD}$. ${ }^{*} P$ values. (F) Histological images of T24/Mock and T24/GRIK2 cells. H\&E and GRIK2 immunohistochemical staining of T24/Mock and T24/GRIK2 tumors. Black bar is $50 \mu \mathrm{m}$. 
UCs. Expression of GRIK2 was not seen in the normal urothelial epithelium, and GRIK2 expression was found in UC tissues. Functional assays revealed that GRIK2 has roles in invasion ability, sphere-forming ability and tumorigenicity in vivo. Furthermore, GRIK2 expression in UC tissues was associated with pathological N stage, tumor grade and lymphovascular invasion (Table 2). Molecular mechanisms of GRIK2 is still elusive in current study; however, GRIK2 knockdown experiments revealed that GRIK2 expression is related to expression of ALDH1A1 (data not shown) and ALDH ${ }^{\text {high }}$ cells by ALDEFLUOR assay. Thus, GRIK2 might have a role in $\mathrm{ALDH}^{\text {high }}$ cells. These results indicated that GRIK2 has different roles in gastric cancer and urothelial cancer.

Upper urinary tract urothelial carcinomas including renal pelvic caner and ureteral cancer are uncommon and account for only 5-10\% of UCs [23]. Patients with localized upper urinary tract carcinoma usually underwent total nephroureterctomy for standard therapy. It is challenging to predict recurrence, and upper urinary tract carcinoma patients with recurrence have a very poor prognosis, even if systemic chemotherapy is performed. Expression of GRIK2 and that of ALDH1 were associated with poor prognosis after nephroureterectomy. These results indicated that GRIK2 expression and ALDH1 expression in patients with UC could be prognostic factors after nephroureterectomy.

In summary, we found that a UC cell line with high ALDH1 activity had CSC/CIC properties. GRIK2 is expressed in UC CSCs/CICs and has roles in invasion, sphere formation and tumorigenicity. GRIK2 expression combined with ALDH1 activity might be a novel prognostic marker for UCs.

\section{MATERIALS AND METHODS}

\section{Ethics statement}

Mice were maintained and experimented on in accordance with the guidelines after approval by the Committee of Sapporo Medical University (No.10-032). All studies were approved by Institutional Review Boards (IRB) of Sapporo Medical University (No. 22-45).

\section{Cell lines}

Human urothelial carcinoma cell lines UM-UC3, T24, HT1376, SW780, TCCSUP, 5637 and J82 (American Type Culture Collection (ATCC), Manassas, VA, USA) were cultured in Dulbecco's modified Eagle's medium (DMEM) (Sigma-Aldrich, St Louis, MO, USA), and the human urothelial papilloma cell line RT4 (ATCC) was cultured in McCoy's 5A medium (Life Technologies, Carlsbad, CA, USA) supplemented with $10 \%$ fetal bovine serum (FBS). PLAT-A cells (kind gifts from Dr. T Kitamura, Tokyo, Japan) were cultured in DMEM supplemented with $10 \% \mathrm{FBS}, 10 \mu \mathrm{g} / \mathrm{ml}$ blasticidin and $1 \mu \mathrm{g} / \mathrm{ml}$ puromycin (Sigma-Aldrich). Cells were incubated in a $37^{\circ} \mathrm{C}$ incubator with humidified air and $5 \% \mathrm{CO}_{2}$.

\section{ALDEFLUOR assay and fluorescence-activated cell sorting isolation}

Aldehyde dehydrogenase 1 (ALDH1) activity was measured as described previously using the ALDEFLUOR assay kit (STEMCELL Technologies, Vancouver, Canada) [9]. Briefly, cells were suspended

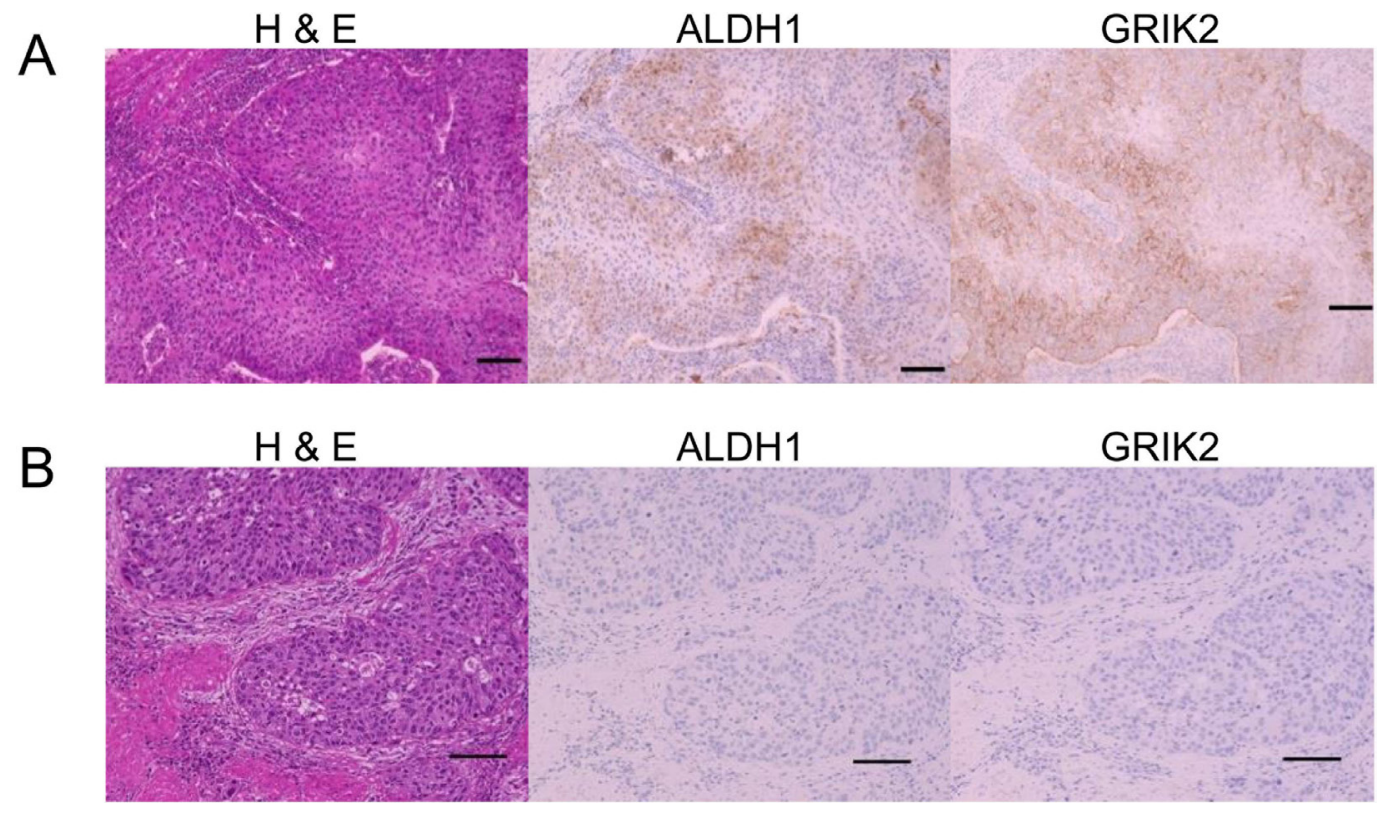

Figure 5: Histological images of H\&E, ALDH1 immunohistochemical staining and GRIK2 immunohistochemical staining. (A) Positive ALDH1 and GRIK2 expression in tumor cells. (B) Negative ALDH1 and GRIK2 expression in tumor cells. 
in ALDEFLUOR assay buffer containing the ALDH1 substrate boron-dipyrromethene-aminoacetaldehyde $\left(1 \mu \mathrm{mol} / 1 / 1 \times 10^{6}\right.$ cells $)$ and incubated for 30 minutes at $37^{\circ} \mathrm{C}$. As a negative control, aliquots of each sample were treated with $50 \mathrm{mmol} / \mathrm{l}$ of the specific ALDH1 inhibitor diethylaminobenzaldehyde. Stained cells were analyzed using a FACSAria II cell sorter. Sorting gates were established using propidium iodide-stained cells for viability.

\section{RNA preparation and RT-PCR analysis}

Total RNA isolation and RT-PCR analysis were performed as described previously [24]. Human Multiple Tissue cDNA Panels I and II (Takara Bio Inc., Otsu, Japan) were used as templates of normal adult tissue cDNAs. The primer pairs used for RT-PCR analysis were 5'-TGTTAGCTGATGCCGACTTG-3' and 5'-CATCACAACCACGTTTCCAG-3' for

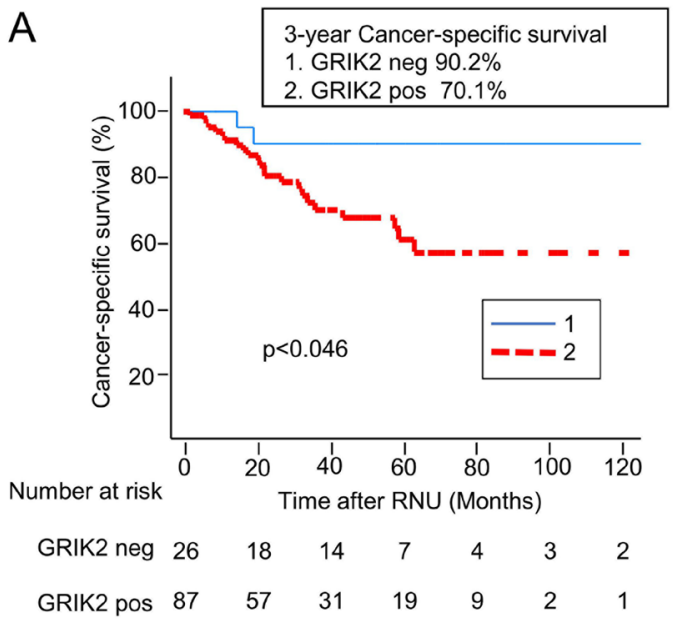

ALDH1A1 with an expected PCR product size of 154 bp, 5'- TACCCAGCGGAACTGTAACC-3' and 5'- CCTCCACCATTTCTCCTTCA-3' for GRIK2 with an expected PCR product size of $166 \mathrm{bp}$, and 5'- ACCACAGTCCATGCCATCAC-3' and 5'TCCACCACCCTGTTGCTGTA-3' for GAPDH with an expected PCR product size of $452 \mathrm{bp}$.

\section{Western blot}

Western blots were performed as described previously [25]. Briefly, $1 \times 10^{5}$ of ALDH $1{ }^{\text {high }}$ cells and ALDH $1^{\text {low }}$ cells were lysed in $40 \mu \mathrm{L}$ of SDS sample buffer. Anti-ALDH1 mouse monoclonal antibody (clone: 44/ ALDH; BD Biosciences, San Jose, CA, USA) was used at 500 -times dilution. Anti- $\beta$-actin and anti- $\alpha$-tubulin mouse monoclonal antibodies (Sigma-Aldrich) were used as loading controls at 2000-times dilution. Anti-mouse IgG and anti-rabbit IgG second antibodies (KPL, Gaithersburg,

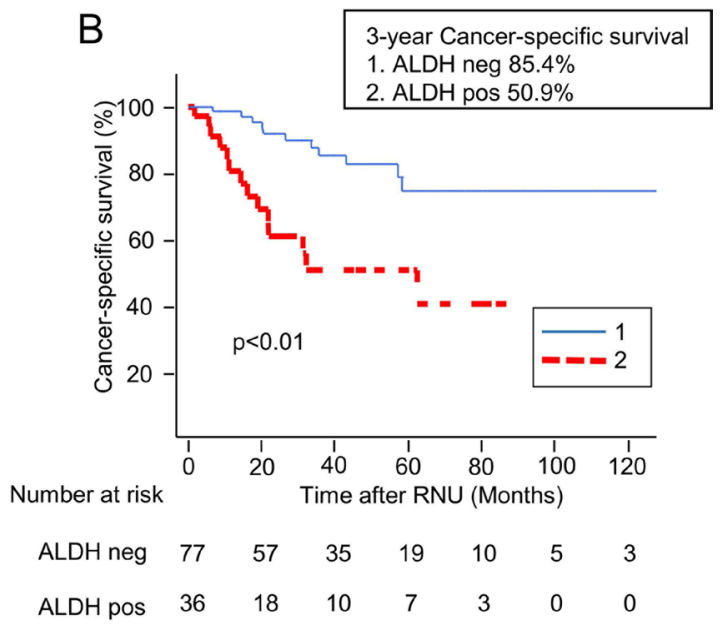

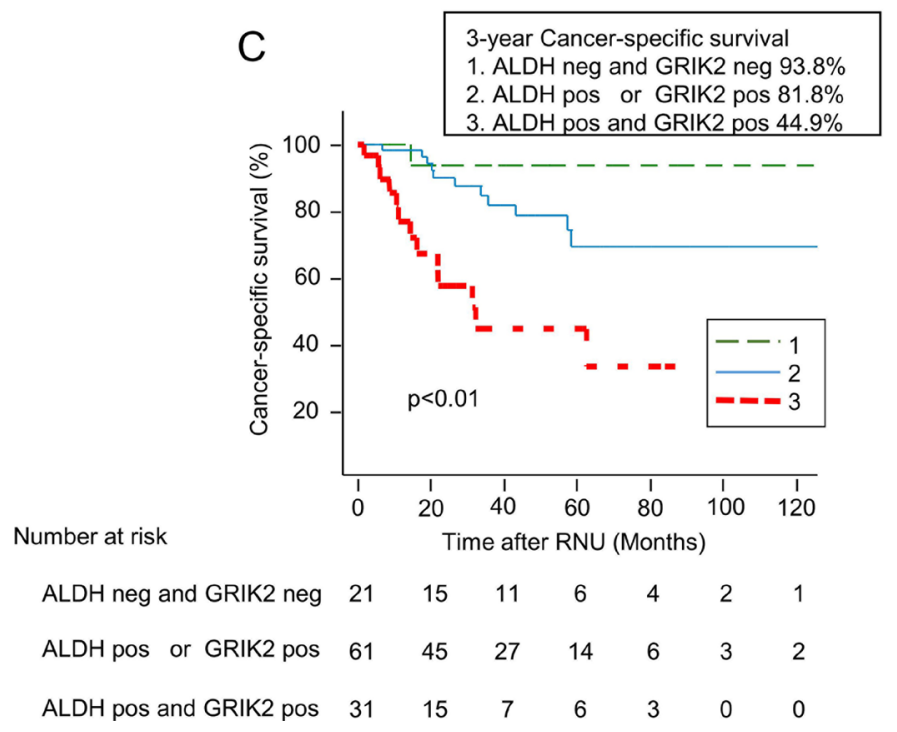

Figure 6: Kaplan-Meier curves for cancer-specific survival rates according to (A) GRIK2 expression status, (B) ALDH1 expression status and $(\mathbf{C})$ combined expression status of GRIK2 and ALDH1. 
MD, USA) were used at 2000-times dilution. The membrane was visualized with Chemiluminescent HRP Substrate (Millipore, Billerica, MA, USA) according to the manufacturer's protocol, and pictures were taken by an Odyssey Fc imaging System (LI-COR, Lincoln, NE, USA).

\section{Sphere-forming assay}

A total of $2 \times 10^{2}$ sorted ALDH $1^{\text {high }}$ and ALDH $1^{\text {low }}$ cells derived from UM-UC3, TCCSUP, J82 and RT4 cells, $5 \times 10^{2}$ si-mediated GRIK2 knockdown cells or T24/Mock and T24/GRIK2 cells were incubated in DMEM/F12 medium (Life Technologies) supplemented with $10 \mathrm{ng} /$ $\mathrm{ml}$ basic fibroblast growth factor and $20 \mathrm{ng} / \mathrm{ml}$ epidermal growth factor (Sigma-Aldrich) in each well of an UltraLow Attachment Surface culture 6-well plate (SigmaAldrich). T24/Mock and T24/GRIK2 cells were incubated with an additional $0.5 \mu \mathrm{g} / \mathrm{ml}$ insulin (Sigma-Aldrich). Spheres larger than $100 \mu \mathrm{m}$ were counted at day 4 or day 5 by light microscopy.

For estimation of $\mathrm{CSC} / \mathrm{CIC}$ frequency, limiting dilution analysis was performed. Serially diluted cells (1/well-1000/well) were cultured in 96-well Ultra-Low Attachment plate and cultured for 7-10 days. Then spherepositive wells were counted. The estimation of CSC/CIC frequency was calculated by ELDA web site (http://bioinf. wehi.edu.au/software/elda/) [26].

\section{Xenograft transplantation in NOD/SCID mice}

Isolated ALDH1 $1^{\text {high }}$ and ALDH1 ${ }^{\text {low }}$ cells or T24/ Mock and T24/GRIK2 cells were resuspended at concentrations of $1 \times 10^{3}$ cells in phosphate buffered saline and Matrigel (BD Biosciences) mixture (1:1). ALDH1 ${ }^{\text {high }}$ and ALDH1 ${ }^{\text {low }}$ cells were injected subcutaneously into the right and left mid back areas of anesthetized non-obese diabetic/severe combined immunodeficient (NOD/SCID) female mice (Charles River Laboratory Japan, Yokohama, Japan) at the age of 4-6 weeks. Tumor growth was monitored weekly, and tumor volume was calculated by $\mathrm{XY}^{2} / 2(\mathrm{X}=$ long axis, $\mathrm{Y}=$ short axis $)$.

\section{Matrigel invasion assay}

Cellular potential for invasiveness was determined using Matrigel invasion chambers (BD Biosciences) according to the manufacturer's instructions [10]. Briefly, a total of $1 \times 10^{4}$ sorted ALDH1 $1^{\text {high }}$ and ALDH1 ${ }^{\text {low }}$ cells, $2 \times 10^{4}$ si-mediated GRIK2 knockdown cells or T24/ Mock and T24/GRIK2 cells were seeded in the upper chambers in serum-free DMEM. The outer chambers were filled with the same medium but with $10 \% \mathrm{FBS}$ as a chemoattractant. Cells were incubated for 24 to 48 hours. Invasive cells were stained with hematoxylin, mounted on slides, and counted by light microscopy. Each experiment was repeated 3 times.

\section{Resistance to cisplatin}

Isolated ALDH1 $1^{\text {high }}$ and ALDH1 $1^{\text {low }}$ cells were seeded in 96 -well plates at $2 \times 10^{3}$ cells per well. The cells in both populations were treated with cisplatin $(0.5-5.0 \mu \mathrm{g} / \mathrm{ml})$. After 48 hours of incubation, viability of the cells was determined using the cell counting kit WST-1 (Dojindo Molecular Technologies, Kumamoto, Japan).

\section{cDNA microarray}

RNA from ALDH1 ${ }^{\text {high }}$ cells was labeled with $\mathrm{Cy} 5$ dye, and RNA from ALDH1 $1^{\text {low }}$ cells was labeled with $\mathrm{Cy} 3$ dye. The probe mixture was hybridized for 40 hours at $65^{\circ} \mathrm{C}$ to a G4412A Human Genome CGH Microarray Kit 105A (Agilent Technologies, Tokyo, Japan). The array was scanned after washing with a G2565BA Microarray Scanner, and fluorescent signals were acquired using Feature Extraction software (Agilent Technologies). The average expression ratio of $\mathrm{Cy} 5$ to $\mathrm{Cy} 3$ was determined per gene.

A dye swap experiment was also done to label $\mathrm{ALDH} 1^{\text {high }}$ and $\mathrm{ALDH} 1^{\text {low }}$ cells with $\mathrm{Cy} 3$ and $\mathrm{Cy} 5$, respectively. An average ratio of more than 2.0, reproducible in two experiments, was determined to indicate differential up-regulation in ALDH1 $1^{\text {high }}$ cells [10]. Microarray raw data and processed data have been deposited in the NCBI GEO database (GSE66684).

\section{siRNA-mediated knockdown}

GRIK2 siRNAs (SR301950A, SR301950B and SR301950B) were purchased from OriGene Technologies (Rockville, MD, USA). siRNA transfection was performed using lipofectamine RNAi MAX reagent (Life Technologies) according to the protocol of the manufacturer. Cells were transfected with siRNA at final concentration of $25 \mathrm{pmol} / 2 \mathrm{~mL}, 24$ hours before analysis. Non-targeting siRNA (OriGene) was used as a negative control. GRIK2 knockdown was confirmed by quantitative real-time PCR.

\section{Retroviral gene transduction and generation of stable transformants}

Transduction of genes into cells was performed by a retrovirus-mediated method as described previously [27]. PLAT-A cells were transiently transduced with a pMXspuro (kind gift from Dr. T. Kitamura, Tokyo, JAPAN) retroviral vector expressing GRIK2 and a control plasmid using FuGENE HD transfection reagent (Promega, Tokyo, Japan) following the manufacturer's protocol. Retroviral 
supernatants were harvested 48 hours after transfection. The supernatant was used for infection of T24 cells in the presence of $8 \mu \mathrm{g} / \mathrm{ml}$ of polybrene (Sigma-Aldrich) overnight. For the generation of stable transformants, the infected cells were selected with $1 \mu \mathrm{g} / \mathrm{ml}$ puromycin (Sigma-Aldrich).

\section{Quantitative real-time PCR analysis}

Quantitative real-time PCR was performed as previously described. [28] ALDH1A1, GRIK2 and GAPDH probes were designed by the manufacturer (TaqMan Gene expression assay; Life Technologies).

\section{Immunohistochemical staining and scoring}

Immunohistochemical (IHC) staining and scoring were done as previously described [15]. To detect ALDH1 and GRIK2 proteins, we used anti-ALDH1 mouse monoclonal antibody (clone: 44/ALDH; BD Biosciences) at 1000-times dilution and anti-GRIK2 rabbit monoclonal antibody (clone: EPR6307; abcam, Tokyo, Japan) at 500-times dilution. All specimens were reviewed by a pathologist who was blinded to clinicopathological data (YH). For ALDH1, a tumor presenting at least one ALDH1positive cancer cell was considered to be ALDH1-positive. For GRIK2, a tumor presenting more than 1\% GRIK2positive cancer cells was considered to be GRIK2-positive.

\section{Patients}

We reviewed the clinical pathology archives of 113 patients who underwent radical nephroureterectomy because of upper urinary tract urothelial carcinoma at Sapporo Medical University Hospital from January 1998 to September 2011.

\section{Statistical analysis}

Data are presented as means $\pm \mathrm{SD}$. Differences in variables were assessed using Student's $t$-test. Survival curves were constructed according to the Kaplan-Meier method. Statistical significance was determined by the logrank test. $P<0.05$ was considered significant. Statistical analysis was done with jmp9 software (SAS institute).

\section{Abbrivations}

$\mathrm{CSC} / \mathrm{CIC}$, cancer stem-like cell/cancer-initiating cell, CIC; UC, urothelial carcinoma; ALDH1, aldehyde dehydrogenase 1A1; GRIK2, glutamate receptor, ionotropic, kainate 2; DEAB, diethylaminobenzaldehyde.

\section{ACKNOWLEDGMENTS AND FUNDING}

This study was supported by a Grant-in-Aid for Scientific Research from the Ministry of Education,
Culture, Sports, Science and Technology of Japan (to N.S.), program for developing the supporting system for upgrading education and research from the Ministry of Education, Culture, Sports, Science and Technology of Japan (to N.S.), Health and Labor Sciences Research Grants, a grant-in-aid of Ono Cancer Research Fund (to T.T.), Suharakinenzaidan Co., Ltd. (to Y.H.), Grants-inAid for Regional R\&D Proposal-Based Program from Northern Advancement Center for Science \& Technology of Hokkaido Japan (to Y.H. and T.T.) and the project for development of innovative research on cancer therapeutics from Japan Agency for Medical Research and development, AMED.

\section{CONFLICTS OF INTEREST}

The authors have no conflicts of interest.

\section{REFERENCES}

1. von der Maase H, Hansen SW, Roberts JT, Dogliotti L, Oliver T, Moore MJ, Bodrogi I, Albers P, Knuth A, Lippert CM, Kerbrat P, Sanchez Rovira P, Wersall P, et al. Gemcitabine and cisplatin versus methotrexate, vinblastine, doxorubicin, and cisplatin in advanced or metastatic bladder cancer: results of a large, randomized, multinational, multicenter, phase III study. J Clin Oncol. 2000; 18:3068-3077.

2. Clarke MF, Dick JE, Dirks PB, Eaves CJ, Jamieson CH, Jones DL, Visvader J, Weissman IL, Wahl GM. Cancer stem cells - perspectives on current status and future directions: AACR Workshop on cancer stem cells. Cancer Res. 2006; 66:9339-9344.

3. Hirohashi Y, Torigoe T, Inoda S, Takahashi A, Morita R, Nishizawa S, Tamura Y, Suzuki H, Toyota M, Sato N. Immune response against tumor antigens expressed on human cancer stem-like cells/tumor-initiating cells. Immunotherapy. 2010; 2:201-211.

4. Chan KS, Espinosa I, Chao M, Wong D, Ailles L, Diehn M, Gill H, Presti J Jr, Chang HY, van de Rijn M, Shortliffe L, Weissman IL. Identification, molecular characterization, clinical prognosis, and therapeutic targeting of human bladder tumor-initiating cells. Proc Natl Acad Sci U S A. 2009; 106:14016-14021.

5. He X, Marchionni L, Hansel DE, Yu W, Sood A, Yang J, Parmigiani G, Matsui W, Berman DM. Differentiation of a highly tumorigenic basal cell compartment in urothelial carcinoma. Stem cells. 2009; 27:1487-1495.

6. Zhang Y, Wang Z, Yu J, Shi J, Wang C, Fu W, Chen Z, Yang J. Cancer stem-like cells contribute to cisplatin resistance and progression in bladder cancer. Cancer Lett. 2012; 322:70-77.

7. She JJ, Zhang PG, Wang ZM, Gan WM, Che XM. Identification of side population cells from bladder cancer cells by DyeCycle Violet staining. Cancer Biol Ther. 2008; 7:1663-1668. 
8. Su Y, Qiu Q, Zhang X, Jiang Z, Leng Q, Liu Z, Stass SA, Jiang F. Aldehyde dehydrogenase 1 A1-positive cell population is enriched in tumor-initiating cells and associated with progression of bladder cancer. Cancer Epidemiol Biomarkers Prev. 2010; 19:327-337.

9. Ginestier C, Hur MH, Charafe-Jauffret E, Monville F, Dutcher J, Brown M, Jacquemier J, Viens P, Kleer CG, Liu S, Schott A, Hayes D, Birnbaum D, et al. ALDH1 is a marker of normal and malignant human mammary stem cells and a predictor of poor clinical outcome. Cell stem cell. 2007; 1:555-567.

10. Nishida S, Hirohashi $\mathrm{Y}$, Torigoe $\mathrm{T}$, Kitamura $\mathrm{H}$, Takahashi A, Masumori N, Tsukamoto T, Sato N. Gene expression profiles of prostate cancer stem cells isolated by aldehyde dehydrogenase activity assay. J Urol. 2012; 188:294-299.

11. Kuroda T, Hirohashi Y, Torigoe T, Yasuda K, Takahashi A, Asanuma H, Morita R, Mariya T, Asano T, Mizuuchi M, Saito T, Sato N. ALDH1-High Ovarian Cancer StemLike Cells Can Be Isolated from Serous and Clear Cell Adenocarcinoma Cells, and ALDH1 High Expression Is Associated with Poor Prognosis. PloS one. 2013; 8:e65158.

12. Yasuda K, Torigoe T, Morita R, Kuroda T, Takahashi A, Matsuzaki J, Kochin V, Asanuma H, Hasegawa T, Saito T, Hirohashi Y, Sato N. Ovarian cancer stem cells are enriched in side population and aldehyde dehydrogenase bright overlapping population. PloS one. 2013; 8:e68187.

13. Michifuri Y, Hirohashi Y, Torigoe T, Miyazaki A, Fujino J, Tamura Y, Tsukahara T, Kanaseki T, Kobayashi J, Sasaki T, Takahashi A, Nakamori K, Yamaguchi A, et al. Small proline-rich protein-1B is overexpressed in human oral squamous cell cancer stem-like cells and is related to their growth through activation of MAP kinase signal. Biochem Biophys Res Commun. 2013; 439:96-102.

14. Michifuri Y, Hirohashi Y, Torigoe T, Miyazaki A, Kobayashi J, Sasaki T, Fujino J, Asanuma H, Tamura Y, Nakamori K, Hasegawa T, Hiratsuka H, Sato N. High expression of ALDH1 and SOX2 diffuse staining pattern of oral squamous cell carcinomas correlates to lymph node metastasis. Pathology Int. 2012; 62:684-689.

15. Kitamura H, Torigoe T, Hirohashi Y, Asanuma H, Inoue R, Nishida S, Tanaka T, Fukuta F, Masumori N, Sato N, Tsukamoto T. Prognostic impact of the expression of ALDH1 and SOX2 in urothelial cancer of the upper urinary tract. Mod Pathol. 2013; 26:117-124.

16. Paschen W, Blackstone CD, Huganir RL, Ross CA. Human GluR6 kainate receptor (GRIK2): molecular cloning, expression, polymorphism, and chromosomal assignment. Genomics. 1994; 20:435-440.

17. Wu CS, Lu YJ, Li HP, Hsueh C, Lu CY, Leu YW, Liu HP, Lin KH, Hui-Ming Huang T, Chang YS. Glutamate receptor, ionotropic, kainate 2 silencing by DNA hypermethylation possesses tumor suppressor function in gastric cancer. Int $\mathrm{J}$ Cancer. 2010; 126:2542-2552.

18. Qu Y, Dang S, Hou P. Gene methylation in gastric cancer. Clin Chim Acta. 2013; 424:53-65.

19. Multani S, Pradhan S, Saranath D. Gene polymorphisms and oral cancer risk in tobacco habitues. Tumor Biol. 2016; 37:6169-6176.

20. Ozawa S, Kamiya H, Tsuzuki K. Glutamate receptors in the mammalian central nervous system. Prog Neurobiol. 1998; 54:581-618.

21. Falso MJ, Buchholz BA, White RW. Stem-like cells in bladder cancer cell lines with differential sensitivity to cisplatin. Anticancer Res. 2012; 32:733-738.

22. Li G, Oswald RE, Niu L. Channel-opening kinetics of GluR6 kainate receptor. Biochemistry. 2003; 42:1236712375.

23. Roupret M, Zigeuner R, Palou J, Boehle A, Kaasinen E, Sylvester R, Babjuk M, Oosterlinck W. European guidelines for the diagnosis and management of upper urinary tract urothelial cell carcinomas: 2011 update. Euro Urol. 2011; 59:584-594.

24. Nakatsugawa M, Hirohashi $Y$, Torigoe $T$, Asanuma $H$, Takahashi A, Inoda S, Kiriyama K, Nakazawa E, Harada K, Takasu H, Tamura Y, Kamiguchi K, Shijubo N, et al. Novel spliced form of a lens protein as a novel lung cancer antigen, Lengsin splicing variant 4. Cancer Sci. 2009; 100:1485-1493.

25. Inoda S, Hirohashi $\mathrm{Y}$, Torigoe $\mathrm{T}$, Nakatsugawa $\mathrm{M}$, Kiriyama K, Nakazawa E, Harada K, Takasu H, Tamura Y, Kamiguchi K, Asanuma H, Tsuruma T, Terui T, et al. Cep55/c10orf3, a tumor antigen derived from a centrosome residing protein in breast carcinoma. J Immunother. 2009; 32:474-485.

26. Hu Y, Smyth GK. ELDA: extreme limiting dilution analysis for comparing depleted and enriched populations in stem cell and other assays. J Immunol Methods. 2009; 347:7078.

27. Nishizawa S, Hirohashi Y, Torigoe T, Takahashi A, Tamura Y, Mori T, Kanaseki T, Kamiguchi K, Asanuma H, Morita R, Sokolovskaya A, Matsuzaki J, Yamada R, et al. HSP DNAJB8 Controls Tumor-Initiating Ability in Renal Cancer Stem-like Cells. Cancer Res. 2012; 72:2844-2854.

28. Takahashi A, Hirohashi Y, Torigoe T, Tamura Y, Tsukahara T, Kanaseki T, Kochin V, Saijo H, Kubo T, Nakatsugawa M, Asanuma H, Hasegawa T, Kondo T, et al. Ectopically expressed variant form of sperm mitochondriaassociated cysteine-rich protein augments tumorigenicity of the stem cell population of lung adenocarcinoma cells. PloS one. 2013; 8:e69095. 